\title{
Soft Power of Massive Open Online Courses: New Age of Digital Diplomacy
}

\author{
Mikhail S. Bukhtoyarov* \\ Siberian Federal University \\ 79 Svobodny, Krasnoyarsk, 660041, Russia
}

Received 26.03.2016, received in revised form 19.04.2016, accepted 25.05.2016

The article addresses the issue of massive open online courses (MOOCs) which are based on the topics of humanities, social sciences and liberal arts. MOOCs developers promote them as the means of open and accessible education. Such courses target at the global audience and they can be efficient in dissemination of knowledge worldwide. Such courses have the capability of becoming a powerful tool for the emerging digital diplomacy. MOOCs can significantly increase the soft power of a political actor: state or non-state.

Keywords: MOOC, digital diplomacy, soft power, knowledge dissemination.

DOI: 10.17516/1997-1370-2016-9-7-1631-1636.

Research area: culture studies.

\section{Massive open online courses}

Massive open online courses (MOOCs) are a rapidly evolving phenomenon within the growing domain of the online education market. MOOCs are usually defined as the university or pre-university level online courses which are provided for unlimited audience with no charge, or with freely accessible content and relatively inexpensive end-of-completion certificates (Wulf, Blohm, Brenner, Leimeister, 2014). Such courses can attract up to several hundred thousand participants from different regions of the world. Among educational professionals there are ongoing debates on the problems of "openness" and "massiveness" and the effectiveness of such courses. Nevertheless, by 2015 several hundreds of universities have been offering and developing thousands of MOOCs on the wide spectrum of topics. These courses are based on different pedagogies and teaching philosophies, they vary in instructional methods and utilization of the online tools, but they are offered to the public as massive open online courses.

First MOOCs appeared in 2008. But it was 2012 , "the year of MOOCs" when their popularity grew significantly and the phenomenon of MOOCs gained world recognition (Pappano, 2012). In 2012-2015 several global MOOC projects were founded either by top-ranked universities or by IT companies in cooperation with such universities. In the span of five years MOOC have become one of the popular trends in online learning. Initially MOOCs drew a lot of public and media attention and were

(C) Siberian Federal University. All rights reserved

* Corresponding author E-mail address: mikebukhtoyarov@gmail.com 
even called "revolution in higher education" (Friedman, 2013). Later the analysis of the large-scale MOOC projects demonstrated the major problem: such courses have extremely low completion rates which are less than $7 \%$ (Jordan, 2014). One more problem is the economy of the such courses: there are several business models developed for MOOCs but they are not efficient enough to support the high cost investments (de Langen, 2013).

However, the unprecedented media attention and the high levels of public interest in the topic have revealed the potential of the open online education as the means of knowledge dissemination. It also may be interpreted as the growing need for such public educational media.

\section{Audience of MOOCs}

The audience of MOOCs is diverse and global. MOOC providers cannot compete with the most popular social networks, but they count millions of users worldwide. For example, Coursera which is one of the largest MOOC projects in 2015 has more than 14 million users (Coursera, 2015).

There are regions and countries where the number of MOOC participants is significantly higher. For example, according to the 2013 report by Universities UK the number of participants from North America, Europe and Asia was much higher than from Africa, South America and Oceania (Universities UK, 2013). There is also a significant difference in the completion rates, ages, level of education, etc. However this audience possesses a number of characteristic features which are defined by the "nature" of MOOCs:

- $\quad$ age limit (13+ for most courses),

- high level of literacy and, particularly, media literacy,

- self-management skills,

- motivation for learning,
- interest in alternative types of education,

- access to the internet, mostly broadband.

The ability to complete a MOOC is also a very important marker of the higher motivation level, goal-orientedness, learning abilities. Though the courses are called "massive" they have potential of working with specific groups or even individuals inside the course.

MOOC participants generate large amounts of data which can be used to find objective criteria for classification of learners. For example, Phillip Hill developed a classification of MOOC students according to the participation patterns (Hill, 2013). René F. Kizilcec, Chris Piech and Emily Schneider used the criterion of student engagement (Kizilcec, Piech, Schneider, 2013). Yvonne Belanger and Jessica Thornton found difference in enrollment motivation and factors that influence course completion (Belanger, Thornton, 2013).

The value of such classifications can be very high due to the potential opportunity of working out the variety of approaches to different groups and to increase the user acceptance of the information. This establishes highly efficient environment for knowledge dissemination.

MOOCs also provide virtually unlimited opportunities for the global research and management in the field of human resource: the tools for student assessment and the data about user behaviour can be utilized for continuous monitoring of the individuals and groups participating in the courses. Moreover, this behaviour can be directed through the course activities (tasks, forums, peer reviewing, collaborative activities and projects, etc.). Such tools, integrated with the growing potential on "big data" analytics have probably never been available for the purposes of the human resource management. 


\section{MOOCs and Digital Diplomacy}

Digital Diplomacy is a relatively new term that describes the use of the information and communication technologies for establishing and supporting the relations between individuals, groups and institutions. It is mostly used in relation to the Web and the Social Web. This term was coined in early 2000s. Digital diplomacy can be viewed as an efficient type of the public diplomacy that specifically relies on the digital media, especially Web 2.0.

The most popular tools which are currently used for the purposes of the digital diplomacy are the social media websites which evolved in 20032010 as the core of Web 2.0: social networking sites (Facebook, VK, Google+), blogging and microblogging platforms (Livejournal and Twitter), video hosting sites (YouTube, Vimeo), wikis (Wikipedia), forums, file sharing services (WikiLeaks). The rapid and intensive exchange of ideas and opinions in the digital environment can significantly influence the public opinion. Most social media rely on the principles of sharing and redistribution of the content, and they are based on the "many-to-many" knowledge circulation model. In this model, the users of social media act as peers inside the constantly changing social network.

MOOC websites inherit some features of the popular social media. MOOC participants have personal accounts, and the learning management system usually stores large amount of personal data. It also tracks their achievements and interests in particular topics. Nearly all the MOOCs offer discussion boards where course members share ideas and links. Many course developers also support the idea of selforganization and self-management of the virtual community that emerges around the course. Its members can use the wide spectrum of tools for sharing user-generated content: wikis, blogs, cloud file storages or organize videoconferences.
Also, many courses have their pages, groups, hashtags on popular social media platforms.

On the contrary to the social media, most of the current courses are built in accordance to the "one-to-many" knowledge distribution model. The role of a student in a MOOC is to some degree opposite to role of a user in other types of social media: every participant of the course (a student) has to follow the steps which were developed by the course designer (the teacher) and accept the rules which are defined in the course syllabus. One more very important feature is the ability of the teacher to get feedback from the audience and monitor any individual or group activities inside the course.

Such combination of features makes MOOCs a unique tool for the purposes of digital diplomacy: the course designer can not only introduce a particular set of ideas through the content of the course, but also track the level of their acceptance by the audience. MOOCs on social science, liberal arts and humanities are potentially the most suitable tools for the purposes of digital diplomacy, as they are designed to be efficient in dissemination of particular philosophical, ethical, or even political ideas.

Potentially, any MOOC can have unlimited number of participants. One of the most popular MOOCs of 2012-2013 with more than 220,000 registered students was the course from Duke University on the topics of critical thinking and philosophy of reasoning "Think Again: How to Reason" (Think Again: How to Reason and Argue. A Duke University Coursera MOOC, 2012-2013. Report). A successful course can be repeated if the owners of the course find it useful.

The number of MOOCs is rapidly growing. According to the Class Central portal which aggregates information about MOOCs, in JuneJuly 2015 more than 500 courses on business and management, more than 300 courses on humanities and more than 350 courses on social 
sciences were available on different MOOC portals. By December 2015 the numbers have increased: more than 700 courses on business and management, nearly 400 courses on humanities, and 450 courses on social sciences (Class Central, 2015). Such significant increase (tens of percent) in a relatively short timespan means that the popularity of such courses has not reached its peak.

MOOCs have the capacity to influence all the four areas of digital diplomacy highlighted by N. Westcott (Westcott, 2008): service delivery, ideas, networks, and information. They offer educational services transnationally and they are used to disseminate ideas, build social networks, collect and analyze large amounts of data.

\section{Soft Power and MOOCs}

Since Joseph S. Nye coined the term "soft power" in 1990 the topic of using digital, and, especially, social media for dissemination of ideologically charged content has grown rapidly. From this perspective any cultural or educational content that is openly distributed over the borders can be viewed as a part of the political process.

MOOCs are no exception. Moreover, the fact that MOOC developers are targeting at the global audience turns any successful MOOC provider into an important political actor that can compete with the national state in one of the mostly sensitive and state-regulated social spheres: education. Academic institutions stepped into the field of public diplomacy long ago and they have formed the modern vision of the global scientific community with very complex policies and regulated information flows. However, education has been the national priority and national interest for most developed countries. Rapid emergence of the online learning and, particularly, MOOCs can be viewed as the powerful means for challenging the national systems of education and breaking their monopoly.
MOOCs are currently not regulated by the national educational standards. They do not fall under the regulations of credit transfer systems of universities. Moreover they are not bound by the existing academic traditions and stereotypes, or can be very flexible on them. MOOCs form the domain of alternative education. Universities and individual teachers can freely define the content, the activities, the parameters of such courses. This fact leaves plenty of opportunities for the experiments in the area of digital diplomacy. MOOCs can become an important environment for exercising the soft power, which, according to Nyle is mostly the power of non-state political actors (Nye, 1990). The political role of the universities and other players of the education market is growing with the development of efficient educational technologies and with the new ways to provide their educational services to the masses. MOOCs can increase their power to a very high level.

\section{Conclusion}

In the highly globalized world full of growing information flows, MOOCs prove that it is possible to combine two very important and powerful political and socioeconomic functions: bring the educational content of particular quality to the masses, and manage the large virtual communities which are formed on the basis of common interest to particular themes (the so-called "communities of interest" and "community of purpose"). Those organizations and individuals who develop and provide such courses obtain unique tools for the global experiments in the fields of online learning, knowledge dissemination, collective online behavior and virtual community management. In comparison to the popular social media format, the format of MOOCs addresses the specific audience aimed at education, development and looking for the ways of productive utilization of the Web. The growing popularity of MOOCs 
and other open educational initiatives leads to the emergence of the global educational networks which make the alternative for the national, regional and local education markets.

Such educational innovations bring the potential threat to the political actors, especially states, because they break the traditional educational markets. States can lose the monopoly and control over the education on the national, regional and local levels. The emerging educational networks take their audience to the new level of transnationalism which is hard to block or compete with. The future of these educational networks is not clear but they have the potential for shifting the traditional roles of the stakeholders inside the national educational markets, or even for reshaping the national educational systems. And MOOCs play an important part in this process.

MOOCs, as any other form of soft power are not a direct threat to the successful states which have their own agenda for the 21 st century politics and prepare themselves for the social change. These courses open education and provide better opportunities to the individuals who want to be a part of the knowledge society. But for the countries with traditionalist educational models and non-flexible political culture MOOCs can become the ultimate challenge. They present educational content and practices from the top schools which are hard to compete with. They make very high stakes and challenge the foundations of traditional approaches to education. Moreover, it is not only the content, but also the technology and the framework of MOOCs that works for openness of the knowledge and for diversity of the audience. The challenge for the national states is to integrate this emerging educational innovation and to harmonize the new wave of the Enlightenment and their political interests.

\section{References}

Belanger, Y., \& Thornton, J. (2013). Bioelectricity: A quantitative approach - Duke University's first MOOC. Available at: http://dukespace.lib.duke.edu/dspace/bitstream/handle/10161/6216/Duke_ Bioelectricity_MOOC_Fall2012.pdf

Class Central. (2015). https://www.class-central.com/

Coursera. (2015). https://www.coursera.org/

Dizard, W. P. (2001). Digital diplomacy: US foreign policy in the information age. Greenwood Publishing Group.

Friedman, T. (2013). Revolution hits the universities. The New York Times, 26(1), 2013. Available at: http://www.nytimes.com/2013/01/27/opinion/sunday/friedman-revolution-hits-the-universities. html?_r=0

Hill, P. (2013). Combining MOOC Student Patterns Graphic with Stanford Analysis. 2013-10-01. Available at: http://mfeldstein. com/combining-mooc-student-patterns-graphic-stanford-analysis

Jordan, K. (2014). Initial trends in enrolment and completion of massive open online courses. The International Review Of Research In Open And Distributed Learning, 15(1).

Kizilcec, R. F., Piech, C., \& Schneider, E. (2013, April). Deconstructing disengagement: analyzing learner subpopulations in massive open online courses. Proceedings of the third international conference on learning analytics and knowledge, pp. 170-179.

de Langen, F. H. T. (2013). Strategies for sustainable business models for open educational resources. The International Review of Research in Open and Distributed Learning, 14(2), pp. 53-66. 
Nye, J. S. (1990). Soft power. Foreign policy, pp. 153-171.

Pappano, L. (2012). The Year of the MOOC, The New York Times, 2(12), 2012.

Think Again: How to Reason and Argue. A Duke University Coursera MOOC, 2012-2013. Report. Available at: http://dukespace.lib.duke.edu/dspace/bitstream/handle/10161/7994/think_again_ report_2013.pdf?sequence=1.

UniversitiesUK(2013)MassiveOpenOnlineCourses:HigherEducation'sDigitalMoment? Available at: http:/www.universitiesuk.ac.uk/highereducation/ Documents/2013/MassiveOpenOnlineCourses. pdf.

Westcott, N. (2008). Digital diplomacy: The Impact of the internet on international relations.

Wulf, J., Blohm, I., Leimeister, J. M., \& Brenner, W. (2014). Massive Open Online Courses. Business \& Information Systems Engineering, 6(2), pp. 111-114.

\title{
«Мягкая сила» массовых открытых онлайн-курсов: новая эра цифровой дипломатии
}

М.С. Бухтояров

Сибирский федеральный университет Россия, 660041, Красноярск, пр. Свободныгй, 79

\begin{abstract}
В статье рассматриваются массовые открытые онлайн-курсы (МООК), которые посвящены темам в области искусства, гуманитарных и социальных наук. Разработчики МООК продвигают их как средство открытого и доступного образования. Такие курсы предназначеньл для глобальной аудитории и являются эффективным способом для распространения знаний по всему миру. Они могут стать мощңным инструментом зарождающейся циирровой дипломатии. МООК могут значительно увеличить «мягкую силу» участников политических процессов, как государственных, так и негосударственных.
\end{abstract}

Ключевые слова: МООК, ичфровая дипломатия, мягкая сила, распространение знаний.

Научная специальность: 24.00.00 - культурология. 